\title{
EFFECTS OF DRINKING WATER CONTAINING ALUMINUM AND FLUORIDE SALTS ON THE LEARNING BEHAVIOR AND BRAIN NEUROTRANSMITTERS OF MALE RAT OFFSPRING
}

\author{
Amal A. Kinawy ${ }^{1,2^{*}}$ \\ ${ }^{\mathbf{1} B i o l o g y}$ Department, Faculty of Science, Taif University, Kingdom of Saudi Arabia \\ ${ }^{2}$ Psychology Department, Faculty of Arts, Cairo University, Giza, Egypt
}

\begin{abstract}
Article History:
Received: 25 February 2019

Revised: 07 April 2019

Accepted: 11 April 2019

Published Online:

18 April 2019

Keywords:

Aluminum

Fluoride

Learning ability

Neurotoxicity

Rat offspring

*Correspondence:

Amal A. Kinawy

Biology Department, Faculty

of Science, Taif University

Kingdom of Saudi Arabia

E-mail:

amalakinawy@gmail.com
\end{abstract}

\begin{abstract}
The widely existence of aluminum and fluoride in the environment makes the exposure to these pollutants unavoidable. Few studies reported the toxic impact of these pollutants "separately" on the neurotransmitters involved in the cognitive behavior of rodent offspring. The present study aimed to evaluate the potential impact of these pollutants "together" on the amino acid neurotransmitters of different brain regions (cerebral cortex, hypothalamus and hippocampus) and the learning ability of male rat offspring. The rat offspring were exposed to deionized water containing $0.5 \mathrm{~g} \mathrm{AlCl}_{3} / \mathrm{L}, 0.15 \mathrm{~g} \mathrm{NaF} / \mathrm{L}$, or their combination throughout the prenatal period of brain growth in the uterus (via the placenta) and the postnatal period until 70 days old (via lactation and drinking water). The results indicated that the levels of most excitatory and inhibitory amino acid neurotransmitters were significantly affected in the three brain regions of exposed male offspring to $\mathrm{AlCl}_{3}$ and/or $\mathrm{NaF}$, as compared with the control male offspring. In addition, the learning ability was more affected in the male offspring exposed to $\mathrm{AlCl}_{3}$ plus $\mathrm{NaF}$, a finding that indicates a synergistic effect. The alteration in the learning ability of rat offspring exposed to $\mathrm{AlCl}_{3}$ plus $\mathrm{NaF}$ was concomitant with the increase in the cerebral cortical glycine, hypothalamic and hippocampal $\gamma$-aminobutyric acid, and hippocampal glutamate. In conclusion, administration of the $\mathrm{AlCl}_{3}$ plus $\mathrm{NaF}$ was more neurotoxic than each salt alone.
\end{abstract}

\section{INTRODUCTION}

The exposure to aluminum during the early stage of life results in behavioral and biochemical alterations in brain, which are manifested during the maturation period ${ }^{[1]}$. The wide existence of aluminum in the environment and its broad use make the exposure to aluminum unavoidable, and consequently, increase its levels in the drinking water ${ }^{[2]}$. Some researchers found that the aluminum concentrations in the bulk brain samples, neurofibrillary tangles, and amyloid plaques were higher in Alzheimer's disease subjects $^{[3]}$. It is also believed that the infants might be at particular risk of aluminum toxicity because of the immaturity of their blood-brain barrier and the sensitivity of their digestive and renal 
systems ${ }^{[2]}$. In addition, aluminum is able to cross the placenta and deposit in all tissues, especially the brain, and hence induces profoundly deleterious effects in animals' offspring $^{[4]}$. Aluminum forms a stable complex with glutamic acids; therefore, glutamic acid is consequently unable to detoxify ammonia from neurons to produce glutamine ${ }^{[5]}$. Accumulation of ammonia is responsible for the neuronal death, as well as affecting the neurotransmitter system ${ }^{[5]}$. Glutamate (Glu), as a neurotransmitter, has a great majority in the excitatory synapses of mammalian central nervous system and plays an important role in the spatial learning and memory processes ${ }^{[6]}$. Aluminum caused an alteration in Glu levels and glutamate $\alpha$-decarboxylase activities of rat's brain ${ }^{[7]}$. Its administration caused behavioral deficits including incoordination with a memorial deficit, neuroinflammation, and cell loss of spinal cord and motor cortex of treated animals ${ }^{[8,9]}$. Also, a relationship between aluminum toxicity and brain aging was previously reported ${ }^{[10]}$.

Fluoride is found in rock phosphate, cryolite, apatite and volcanic emissions, but drinking water is the primary source of fluoride exposure ${ }^{[11,12]}$. It caused neurotoxicity and impairment in the physiological functions of rats' brain, possibly through enhancing the oxidative stress $^{[12,13]}$. In addition, exposure to high levels of fluoride increased the risk of lowering the children intelligence scores ${ }^{[14,15]}$. Also, rats exposed to fluoride in combination with arsenic showed perturbation and disorder in the neurobehavioral balances ${ }^{[16,17]}$.

Few studies reported the toxic impact of aluminum and fluoride "separately" on neurotransmitters involved in the cognitive behavior of rodent offspring ${ }^{[18,19]}$. In addition, our previous studies reported the synergistic toxicity of these pollutants on brain antioxidant defense system and sensorimotor aspects of rat offspring ${ }^{[20,21]}$. Neverthless, no reports were found in the literature, to the best of my knoweledge, regarding the impact of these polutants "together" on amino acids neurotransmitters involved in the learning ability of rodent offspring. Therefore, the present study aimed to evaluate the disturbances in the learning ability and the levels of amino acid neurotransmitters of different brain regions (cerebral cortex, hypothalamus and hippocampus) of male rat offspring exposed to these pollutants "separately or together" during the prenatal and postnatal periods. The current study focused only on the maze learning test in addition to the inhibitory amino acid neurotransmitters (IAAs) such as glycine (Gly) and $\gamma$-aminobutyric acid (GABA), as well as the excitatory amino acid neurotransmitters (EAAs) such as Glu and aspartate (Asp).

\section{MATERIAL AND METHODS Experimental animals}

Adult female rats weighing $180 \pm 15 \mathrm{~g}$ were obtained from the animal house of the Faculty of Science, Taif University, and housed individually in plastic cages at $20^{\circ} \mathrm{C}$ and 12 hours light/12 hours dark cycle. The mother rats were fed bread and milk during the prenatal and weaning periods. After weaning, the male offspring were given ad libitum access to deionized water and a commercial, balanced pelleted diet for rodents. The food debris and faces were removed daily, to keep sawdust dry throughout the course of experiments. The handling of the animals was strictly in agreement with the Taif University regulations and guidelines for using animals in the research.

\section{Chemicals}

$\mathrm{AlCl}_{3}$ and $\mathrm{NaF}$ with $99 \%$ purity, and all chemicals used for the estimation of the amino acids by reversed-phase high performance liquid chromatography (RPHPLC) were purchased from Sigma-Aldrich, via agency at Saudi Arabia.

\section{Experimental design}

Forty female rats were mated with male rats (1 male/5 female) of the same strain in order to obtain the male rat offspring for the 
present study. The vaginal smears were examined to detect the period of positive estrus, according to the method of Harkness and Wagner ${ }^{[22]}$. After 6 days of gestation, forty pregnant females were randomly divided into four groups (A, B, C, and D), each with ten females. Throughout the prenatal period, the pregnant females of group A received pure drinking deionized water, whereas those of the groups $\mathrm{B}$ to $\mathrm{D}$ exposed to $0.15 \mathrm{~g} \mathrm{NaF} / \mathrm{L}^{[23]}, 0.5 \mathrm{~g} \mathrm{AlCl}_{3} / \mathrm{L}^{[24]}$, and $0.15 \mathrm{~g} \mathrm{NaF}+0.5 \mathrm{~g} \mathrm{AlCl}_{3}$ dissolved in $1.0 \mathrm{~L}$ of deionized water, respectively. After parturition, the mother rats of groups A-D were transferred to the pups through the breastfeeding period and treated as explained above. However, the male offspring were left for the natural maternal care until the weaning period. After the weaning stage, the male offspring in groups II, IV, and VI were exposed to the same levels of aluminum and fluoride salts dissolved in deionized water until 70 days old (postnatal period), i.e. these groups were exposed to these pollutants during the prenatal, lactation and postweaning periods until 70 days old (Table 1). Male offspring of groups III, V, and VII were given pure deionized water only until 70 days old, i.e. these groups were exposed to these pollutants during the prenatal and lactation periods only (Table 1).

Table 1: Experimental design to evaluate the toxicity of aluminum and/or fluoride on male rat offspring throughout the prenatal and postnatal stage until age 70 days old.

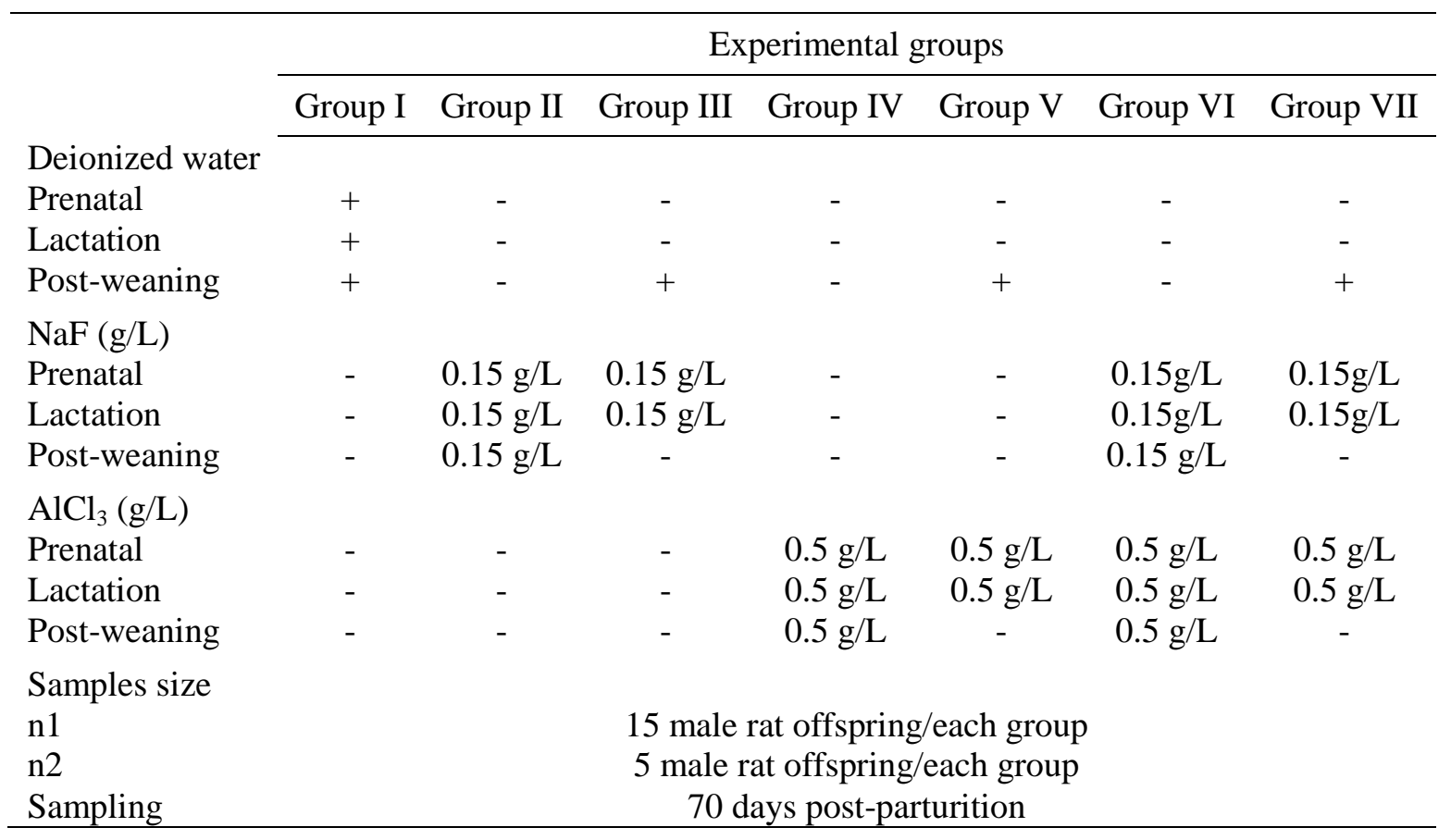

$\mathrm{NaF}$ or $\mathrm{AlCl}_{3}$ were dissolved in deionized water.

n1: sample size of male offspring used in the behavioral experiment; $n 2$ : sample size of male offspring used in the neurotransmitters experiment.

Group I: control male offspring given deionized $\mathrm{H}_{2} \mathrm{O}$ during the prenatal, lactation and postweaning periods until 70 days old; group II: male offspring given $\mathrm{NaF}$ during the prenatal, lactation and post-weaning periods until 70 days old; group III: male offspring given $\mathrm{NaF}$ during the prenatal and lactation periods only; group IV: male offspring given $\mathrm{AlCl}_{3}$ during the prenatal, lactation and post-weaning periods until 70 days old; group $\mathrm{V}$ : male offspring given $\mathrm{AlCl}_{3}$ during the prenatal and lactation periods only; group VI: male offspring given $\mathrm{NaF}+\mathrm{AlCl}_{3}$ during prenatal, lactation and post-weaning periods until 70 days old; group VII: male offspring given $\mathrm{NaF}+\mathrm{AlCl}_{3}$ during the prenatal and lactation periods only. 


\section{Sampling}

At the end of the experimental period, twenty male offspring were withdrawn from each of the 7 groups for the behavioral and amino acid neurotransmitters assays. The sample size required for the behavioral assay was 15 male offspring $(\mathrm{n} 1=15)$, whereas the sample size needed for the estimation of amino acid neurotransmitters were five, $\mathrm{n} 2=5$ (Table 1).

\section{Maze learning test}

Male offspring were deprived of food for 23 hours before the initiation of this test. Then, they were given one trial per day for five consecutive days. The daily amount of food was provided for rats as a reward at the end of the maze. The following measurements were recorded according to the method of Staddon $^{[25]}$ : (a) the elapsed time to reach the food, (b) the number of errors (passage in the blind alleys).

\section{Estimation of amino acid neuro- transmitters}

Male offspring were killed at the end of the experimental period and the brains were rapidly dissected in ice-cold Petri-dishes to isolate the cerebral cortex, hippocampus and hypothalamus. The brain tissues were homogenized in $75 \%$ HPLC grade methanol. After centrifuging the homogenates, the supernatants were used to estimate the concentrations of IAAs and EAAs as previously described ${ }^{[26]}$. This method was based on the quantitative derivatization of amino acids with phenylisothiocyanate. For separation and quantitation of the resulting phenylthiocarbamyl amino acid derivatives by RP-HPLC, the Agilent 1100 Series HPLC Value System with octadecylsilyl reverse-phase column (Agilent Technologies, Waldbronn, Germany) was used. In order to evaluate the resulted amino acid derivatives, the effluent stream was monitored continuously at $254 \mathrm{~nm}$.

\section{Statistical analysis}

Kolmogorov-Smirnov test indicated that the data were normally distributed, and therefore the parametric statistical analyses were performed. One-way analysis of variance (ANOVA) was applied to analyze the effect of treatments on the studied parameters of male offspring, then followed by Duncan's test of homogeneity to compare between all variables at a significant level $\alpha=0.05$ $(P<0.05)$. Statistical analyses were computed by the aid of the IBM Statistical Package for the Social Sciences (SPSS) version 24.

\section{RESULTS}

Effects of $\mathrm{AlCl}_{3}$ and $\mathrm{NaF}$ on brain neurotransmitters of rat offspring

One-way ANOVA affirmed that the concentrations of EAAs and IAAs in the cerebral cortex, hypothalamus and hippocampus of male rat offspring were significantly affected $(P<0.001-0.0001)$ by the treatments with $\mathrm{AlCl}_{3}, \mathrm{NaF}$, and their combination throughout the prenatal and postnatal periods until 70 days old (Tables 2-4). Duncan's test of homogeneity affirmed that the concentrations of IAAs in the three studied brain regions of groups II $(\mathrm{NaF}$ alone), IV ( $\mathrm{AlCl}_{3}$ alone), and $\mathrm{VI}(\mathrm{NaF}+$ $\mathrm{AlCl}_{3}$ ) increased significantly compared with the group I that received only deionized $\mathrm{H}_{2} \mathrm{O}$ throughout the prenatal and postnatal periods (Tables 2-4). The levels of IAAs in the hypothalamus reached the highest concentration in rats exposed to $\mathrm{AlCl}_{3}$ in combination with $\mathrm{NaF}$ (group VI), followed by rats exposed to $\mathrm{AlCl}_{3}$ alone (group IV) and $\mathrm{NaF}$ alone (group II) as shown in Table "3".

The concentrations of the EAAs decreased in the rat offspring as a response to the exposure to $\mathrm{NaF}$ alone (group II) and became statistically lower, in most cases, than rat offspring drinking only deionized water throughout the prenatal and postnatal periods (groups I) as shown in Tables " $2-4$ ". On the other hand, the levels of cerebral cortical and hippocampal EAAs were markedly elevated as a response to the exposure to $\mathrm{AlCl}_{3}$ alone (group IV) and in combination with $\mathrm{NaF}$ (group VI), and became significantly greater than their levels in groups I and II (Tables 2 and 4). The concentrations of EAAs in the hippocampus 
of rats in the group VI were $\geq$ their levels in rats of the group IV > their levels in rats of the groups II (Table 4). The cerebral cortical Glu content of group $\mathrm{V}$ (received $\mathrm{AlCl}_{3}$ during the prenatal and lactation periods only) was significantly greater than that of group III (received $\mathrm{NaF}$ during the prenatal and lactation periods only), whereas the levels of Asp among groups III, V, and VII (received $\mathrm{NaF}+\mathrm{AlCl}_{3}$ during the prenatal and lactation periods only) didn't statistically change (Table 2). The concentrations of EAAs in the hippocampus of group VII were $\geq$ their concentrations in the group $\mathrm{V}>$ their concentrations in the group III (Table 4).

Table 2: Effects of aluminum and fluoride, given separately or in combination, on the levels $(\mu \mathrm{g} / \mathrm{g}$ brain tissue) of excitatory (EAAs) and inhibitory (IAAs) amino acid neurotransmitters in the cerebral cortex of male rat offspring.

\begin{tabular}{lcccc}
\hline & \multicolumn{2}{c}{ IAAs } & \multicolumn{2}{c}{ EAAs } \\
\cline { 2 - 5 } Group I & Glycine & GABA & Glutamate & Aspartate \\
\cline { 2 - 5 } Group II & $4.2 \pm 0.06^{\mathrm{a}}$ & $3.4 \pm 0.05^{\mathrm{a}}$ & $6.2 \pm 0.36^{\mathrm{b}}$ & $5.1 \pm 0.40^{\mathrm{b}}$ \\
Group III & $5.3 \pm 0.24^{\mathrm{b}}$ & $4.4 \pm 0.11^{\mathrm{b}}$ & $4.1 \pm 0.18^{\mathrm{a}}$ & $3.1 \pm 0.11^{\mathrm{a}}$ \\
Group IV & $3.7 \pm 0.24^{\mathrm{a}}$ & $3.5 \pm 0.20^{\mathrm{a}}$ & $5.9 \pm 0.38^{\mathrm{b}}$ & $5.2 \pm 0.52^{\mathrm{b}}$ \\
Group V & $6.4 \pm 0.27^{\mathrm{c}}$ & $6.0 \pm 0.09^{\mathrm{d}}$ & $9.2 \pm 0.89^{\mathrm{e}}$ & $7.5 \pm 0.20^{\mathrm{c}}$ \\
Group VI & $4.2 \pm 0.37^{\mathrm{a}}$ & $4.7 \pm 0.19^{\mathrm{b}}$ & $7.7 \pm 0.61^{\mathrm{c}}$ & $4.9 \pm 0.18^{\mathrm{b}}$ \\
Group VII & $7.1 \pm 0.27^{\mathrm{d}}$ & $5.2 \pm 0.18^{\mathrm{c}}$ & $10.0 \pm 0.59^{\mathrm{e}}$ & $6.7 \pm 0.03^{\mathrm{d}}$ \\
\hline One-way & $3.8 \pm 0.20^{\mathrm{a}}$ & $3.2 \pm 0.05^{\mathrm{a}}$ & $7.2 \pm 0.30^{\mathrm{c}}$ & $5.0 \pm 0.05^{\mathrm{b}}$ \\
ANOVA & $\mathrm{F}_{6,28}=948$ & $\mathrm{~F}_{6,28}=946$ & $\mathrm{~F}_{6,28}=2096$ & $\mathrm{~F}_{6,28}=521$ \\
\hline
\end{tabular}

Data are presented as means \pm standard errors $(\mathrm{n} 1=5)$. In each column, values marked with the same superscript letter are similar (insignificant, $P \geq 0.05$ ).

Table 3: Effects of aluminum and fluoride, given separately or in combination, on the levels $(\mu \mathrm{g} / \mathrm{g}$ brain tissue) of excitatory (EAAs) and inhibitory (IAAs) amino acid neurotransmitters in the hypothalamus of male rat offspring.

\begin{tabular}{lcccc}
\hline & \multicolumn{2}{c}{ IAAs } & \multicolumn{2}{c}{ EAAs } \\
\cline { 2 - 5 } Group I & Glycine & GABA & Glutamate & Aspartate \\
\cline { 2 - 5 } Group II & $2.8 \pm 0.11^{\mathrm{a}}$ & $1.7 \pm 0.14^{\mathrm{a}}$ & $3.8 \pm 0.10^{\mathrm{d}}$ & $3.8 \pm 0.20^{\mathrm{b}}$ \\
Group III & $4.3 \pm 0.12^{\mathrm{c}}$ & $2.5 \pm 0.21^{\mathrm{b}}$ & $2.7 \pm 0.15^{\mathrm{b}}$ & $3.6 \pm 0.07^{\mathrm{b}}$ \\
Group IV & $3.9 \pm 0.17^{\mathrm{b}}$ & $2.4 \pm 0.09^{\mathrm{b}}$ & $3.4 \pm 0.15^{\mathrm{c}}$ & $3.9 \pm 0.18^{\mathrm{b}}$ \\
Group V & $4.8 \pm 0.23^{\mathrm{d}}$ & $2.5 \pm 0.14^{\mathrm{b}}$ & $2.5 \pm 0.10^{\mathrm{b}}$ & $3.4 \pm 0.04^{\mathrm{b}}$ \\
Group VI & $4.3 \pm 0.18^{\mathrm{c}}$ & $2.4 \pm 0.14^{\mathrm{b}}$ & $2.8 \pm 0.11^{\mathrm{b}}$ & $3.7 \pm 0.11^{\mathrm{b}}$ \\
Group VII & $4.9 \pm 0.20^{\mathrm{d}}$ & $3.2 \pm 0.12^{\mathrm{c}}$ & $2.1 \pm 0.14^{\mathrm{a}}$ & $3.0 \pm 0.14^{\mathrm{a}}$ \\
\hline One-way & $4.3 \pm 0.28^{\mathrm{c}}$ & $2.6 \pm 0.15^{\mathrm{b}}$ & $2.5 \pm 0.07^{\mathrm{b}}$ & $3.6 \pm 0.14^{\mathrm{b}}$ \\
ANOVA & $\mathrm{F}_{6,28}=268$ & $\mathrm{~F}_{6,28}=256$ & $\mathrm{~F}_{6,28}=67$ & $\mathrm{~F}_{6,28}=160$ \\
\hline
\end{tabular}

Data are presented as means \pm standard errors $(\mathrm{n} 1=5)$. In each column, values marked with the same superscript letter are similar (insignificant, $P \geq 0.05$ ). 
Table 4: Effects of aluminum and fluoride, given separately or in combination, on the levels $(\mu \mathrm{g} / \mathrm{g}$ brain tissue) of excitatory (EAA) and inhibitory (IAAs) amino acid neurotransmitters in the hippocampus of male rat offspring.

\begin{tabular}{lcccc}
\hline & \multicolumn{2}{c}{ IAAs } & \multicolumn{2}{c}{ EAAs } \\
\cline { 2 - 5 } Group I & Glycine & GABA & Glutamate & Aspartate \\
\cline { 2 - 5 } Group II & $3.7 \pm 0.08^{\mathrm{a}}$ & $2.5 \pm 0.09^{\mathrm{a}}$ & $3.8 \pm 0.10^{\mathrm{b}}$ & $3.0 \pm 0.14^{\mathrm{c}}$ \\
Group III & $7.0 \pm 0.22^{\mathrm{d}}$ & $3.8 \pm 0.16^{\mathrm{c}}$ & $1.8 \pm 0.06^{\mathrm{a}}$ & $2.2 \pm 0.13^{\mathrm{a}}$ \\
Group IV & $6.4 \pm 0.11^{\mathrm{a}}$ & $3.1 \pm 0.38^{\mathrm{b}}$ & $2.1 \pm 0.08^{\mathrm{a}}$ & $2.6 \pm 0.11^{\mathrm{b}}$ \\
Group V & $5.3 \pm 0.22^{\mathrm{d}}$ & $4.9 \pm 0.34^{\mathrm{c}}$ & $3.7 \pm 0.11^{\mathrm{d}}$ \\
Group VI & $6.2 \pm 0.45^{\mathrm{c}}$ & $3.5 \pm 0.06^{\mathrm{c}}$ & $4.0 \pm 0.19^{\mathrm{b}}$ & $3.4 \pm 0.04^{\mathrm{d}}$ \\
Group VII & $5.6 \pm 0.09^{\mathrm{b}}$ & $5.9 \pm 0.22^{\mathrm{e}}$ & $6.8 \pm 0.55^{\mathrm{d}}$ & $3.8 \pm 0.20^{\mathrm{d}}$ \\
\hline One-way & $3.1 \pm 0.04^{\mathrm{b}}$ & $4.8 \pm 0.43^{\mathrm{c}}$ & $3.6 \pm 0.14^{\mathrm{d}}$ \\
ANOVA & $\mathrm{F}_{6,28}=339$ & $\mathrm{~F}_{6,28}=331$ & $\mathrm{~F}_{6,28}=1460$ & $\mathrm{~F}_{6,28}=386$ \\
\hline
\end{tabular}

Data are presented as means \pm standard errors $(\mathrm{n} 1=5)$. In each column, values marked with the same superscript letter are similar (insignificant, $P \geq 0.05$ ).

\section{Effects of $\mathrm{AlCl}_{3}$ and $\mathrm{NaF}$ on learning behavior of rat offspring}

According to the one-way ANOVA, the number of errors and elapsed time in the maze learning test of rat offspring were significantly affected $(P<0.0001)$ by the exposure to $\mathrm{AlCl}_{3}$ and $\mathrm{NaF}$ (Tables 5 and 6). Where, the number of errors and elapsed time in the maze learning test of group II (NaF alone) were statistically higher than that of group III (received $\mathrm{NaF}$ during the prenatal and lactation periods only) throughout the five consecutive days of observation. In addition, the number of errors and elapsed time in the maze learning test of group IV $\left(\mathrm{AlCl}_{3}\right.$ alone $)$ was significantly higher than that of group $\mathrm{V}$ (received $\mathrm{AlCl}_{3}$ during the prenatal and lactation periods only) on almost all days. Moreover, group VI ( $\left.\mathrm{NaF}+\mathrm{AlCl}_{3}\right)$ exhibited a significant increase in the number of errors and elapsed time of the maze learning test as compared with the group VII (received $\mathrm{NaF}+\mathrm{AlCl}_{3}$ during the prenatal and lactation periods only) throughout the five consecutive days. At days 1, 3, and 4 only, the number of errors in the maze learning test of group VI was significantly higher than that of groups II and IV (Tables 5 and 6).

\section{DISCUSSION}

Under normal physiological conditions, brain EAAs and IAAs are in a dynamic equilibrium that has an important role in satisfying the performance of the nervous system $^{[27]}$. Overproduction of EAAs induced continuous hyperactivity, through their specific receptors, leading to excitotoxic damage to neurons that affected learning behavior ${ }^{[18,27]}$. The present study indicated that the chronic exposure to $\mathrm{AlCl}_{3}$ plus $\mathrm{NaF}$, during the pregnancy (prenatal), lactation and post-weaning until 70 days old, greatly affected the learning ability of male rat offspring more than those exposed to $\mathrm{AlCl}_{3}$ alone or $\mathrm{NaF}$ alone. The detrimental effect of $\mathrm{AlCl}_{3}$ and $\mathrm{NaF}$ combination on the learning ability of male rat offspring was due to the increase in the cerebral cortical and hippocampal EAAs by aluminum mainly, since fluoride caused a decrease in EAAs of these two brain regions.

Other researchers also found that the neurotoxicity induced by aluminum was correlated with the alteration induced in the brain Glu-GABA system ${ }^{[28]}$. In addition, the $\mathrm{Ca}^{2+}$ levels in the chicken neurons increased significantly after exposure to aluminum ${ }^{[29]}$. Taking into account that the release of EAAs is $\mathrm{Ca}^{2+}$-dependent ${ }^{[18]}$, the significant increase 
Table 5: Effects of aluminum and fluoride, given separately or in combination, on the number of errors through maze learning test of male rat offspring.

\begin{tabular}{lccccc}
\hline & \multicolumn{5}{c}{ Number of errors in maze } \\
\cline { 2 - 6 } Group I & 1 day & 2 days & 3 days & 4 days & 5 days \\
\cline { 2 - 6 } Group II & $4.7 \pm 0.36^{\mathrm{a}}$ & $4.0 \pm 0.28^{\mathrm{a}}$ & $3.1 \pm 0.35^{\mathrm{a}}$ & $2.4 \pm 0.30^{\mathrm{a}}$ & $1.7 \pm 0.18^{\mathrm{a}}$ \\
Group III & $6.9 \pm 0.35^{\mathrm{c}}$ & $4.9 \pm 0.21^{\mathrm{b}}$ & $4.8 \pm 0.20^{\mathrm{c}}$ & $3.9 \pm 0.26^{\mathrm{b}}$ & $3.4 \pm 0.25^{\mathrm{c}}$ \\
Group IV & $5.8 \pm 0.30^{\mathrm{b}}$ & $4.0 \pm 0.35^{\mathrm{a}}$ & $3.9 \pm 0.30^{\mathrm{b}}$ & $2.6 \pm 0.30^{\mathrm{a}}$ & $2.4 \pm 0.25^{\mathrm{b}}$ \\
Group V & $6.0 \pm 0.24^{\mathrm{b}}$ & $5.5 \pm 0.24^{\mathrm{c}}$ & $5.2 \pm 0.22^{\mathrm{c}}$ & $3.3 \pm 0.33^{\mathrm{b}}$ & $3.7 \pm 0.30^{\mathrm{c}}$ \\
Group VI & $5.7 \pm 0.23^{\mathrm{b}}$ & $4.4 \pm 0.16^{\mathrm{a}}$ & $4.0 \pm 0.24^{\mathrm{b}}$ & $2.7 \pm 0.28^{\mathrm{a}}$ & $2.7 \pm 0.23^{\mathrm{b}}$ \\
Group VII & $7.3 \pm 0.35^{\mathrm{d}}$ & $5.7 \pm 0.25^{\mathrm{c}}$ & $5.5 \pm 0.27^{\mathrm{d}}$ & $4.3 \pm 0.27^{\mathrm{c}}$ & $3.8 \pm 0.33^{\mathrm{c}}$ \\
\hline One-way & $5.7 \pm 0.21^{\mathrm{b}}$ & $5.0 \pm 0.24^{\mathrm{b}}$ & $4.8 \pm 0.24^{\mathrm{c}}$ & $2.1 \pm 0.24^{\mathrm{a}}$ & $2.9 \pm 0.21^{\mathrm{b}}$ \\
ANOVA & $\mathrm{F}_{6,98}=26.2$ & $\mathrm{~F}_{6,98}=32.8$ & $\mathrm{~F}_{6,98}=63.8$ & $\mathrm{~F}_{6,98}=51.8$ & $\mathrm{~F}_{6,98}=49.3$ \\
\hline
\end{tabular}

Data are presented as means \pm standard errors $(\mathrm{n} 2=15)$. In each column, values marked with the same superscript letter are similar (insignificant, $P \geq 0.05$ ).

Table 6: Effects of aluminum and fluoride, given separately or in combination, on the elapsed time through maze learning test of male rat offspring.

\begin{tabular}{lccccc}
\hline & \multicolumn{5}{c}{ Elapsed time through maze (minutes) } \\
\cline { 2 - 6 } Group I & 1 day & 2 days & 3 days & 4 days & 5 days \\
\cline { 2 - 6 } Group II & $2.7 \pm 0.25^{\mathrm{a}}$ & $2.7 \pm 0.25^{\mathrm{a}}$ & $1.3 \pm 0.26^{\mathrm{a}}$ & $0.8 \pm 0.17^{\mathrm{a}}$ & $0.5 \pm 0.13^{\mathrm{a}}$ \\
Group III & $4.3 \pm 0.27^{\mathrm{c}}$ & $3.1 \pm 0.26^{\mathrm{b}}$ & $2.3 \pm 0.15^{\mathrm{b}}$ & $1.5 \pm 0.16^{\mathrm{b}}$ & $1.2 \pm 0.15^{\mathrm{c}}$ \\
Group IV & $2.9 \pm 0.16^{\mathrm{a}}$ & $2.6 \pm 0.21^{\mathrm{a}}$ & $1.7 \pm 0.27^{\mathrm{a}}$ & $0.9 \pm 0.19^{\mathrm{a}}$ & $0.7 \pm 0.18^{\mathrm{a}}$ \\
Group V & $3.7 \pm 0.36^{\mathrm{b}}$ & $3.3 \pm 0.29^{\mathrm{b}}$ & $2.3 \pm 0.18^{\mathrm{b}}$ & $2.1 \pm 0.15^{\mathrm{c}}$ & $1.6 \pm 0.13^{\mathrm{c}}$ \\
Group VI & $3.2 \pm 0.20^{\mathrm{a}}$ & $2.3 \pm 0.21^{\mathrm{a}}$ & $1.7 \pm 0.21^{\mathrm{a}}$ & $1.1 \pm 0.19^{\mathrm{a}}$ & $0.9 \pm 0.18^{\mathrm{b}}$ \\
Group VII & $3.1 \pm 0.19^{\mathrm{c}}$ & $3.7 \pm 0.19^{\mathrm{b}}$ & $2.8 \pm 0.20^{\mathrm{c}}$ & $2.5 \pm 0.13^{\mathrm{c}}$ & $1.6 \pm 0.19^{\mathrm{c}}$ \\
\hline One-way & $3.5 \pm 0.27^{\mathrm{b}}$ & $2.9 \pm 0.18^{\mathrm{a}}$ & $2.1 \pm 0.27^{\mathrm{b}}$ & $1.7 \pm 0.21^{\mathrm{b}}$ & $0.9 \pm 0.18^{\mathrm{b}}$ \\
ANOVA & $\mathrm{F}_{6,28}=22.4$ & $\mathrm{~F}_{6,28}=16.3$ & $\mathrm{~F}_{6,28}=18.1$ & $\mathrm{~F}_{6,28}=15.6$ & $\mathrm{~F}_{6,28}=18.6$ \\
\hline
\end{tabular}

Data are presented as means \pm standard errors $(\mathrm{n} 2=15)$. In each column, values marked with the same superscript letter are similar (insignificant, $P \geq 0.05$ ).

of hippocampal EAAs in the current study may be attributed to the excessive liberation of $\mathrm{Ca}^{2+}$ as a direct response to aluminum exposure. On the other hand, the release of Glu after the exposure to aluminum enhanced the postsynaptic membrane receptors to increase $\mathrm{Ca}^{2+}$ influx. Accumulation of $\mathrm{Ca}^{2+}$ in the mitochondria of nerve cells enhanced the liberation of the reactive oxygen species (ROS) causing oxidative damage of neuron ${ }^{[30,31]}$. However,
GABA and Gly could decrease the liberation of Glu from presynaptic membrane to the synaptic cleft to lower the accumulation of $\mathrm{Ca}^{2+}$, and hence inhibiting and/or blocking EAAs-induced excitotoxicity ${ }^{[32]}$. Aluminum neurotoxicity may also be related to its ability to enhance inflammation (through augmenting the oxidative stress), decrease glucose utilization, affect the process of phosphorylation-dephosphorylation, disturb the rate of transmembrane diffusion, and 
selectively affect the saturable transport systems in the blood-brain barrier ${ }^{[33-37]}$.

On the other hand, few studies reported the adverse effects of fluoride on the hippocampal glu and the memory-associated monoamines in rat offspring and adult rats, respectively ${ }^{[19,38]}$. Fluoride was able to penetrate the placenta and the incomplete blood-brain barrier during the prenatal period and accumulate in the brain tissues of rat offspring ${ }^{[20]}$. The decrease shown in the current study in the EAAs of rat offspring exposed to fluoride only may be explained through its neurodegenerative activity. Where, it caused oxidative damage of brain tissues of rat offspring by: (a) increasing the lipid peroxidation, (b) enhancing the production of superoxide anion and nitric oxide (NOx, a gaseous free radical) to form peroxynitrite that irreversibly prevent mitochondrial respiration, and hence augmented mitochondrial ROS production, (c) decreasing the levels of ascorbic acid (an antioxidant vitamin), the synthesis of reduced glutathione (a nonenzymic antioxidant) and the activity of superoxide dismutase (an enzymic antioxidants) in different brain areas including the cerebral cortex, hippocampus and hypothalamus ${ }^{[20]}$.

The data of the present study indicated a significant disturbance in the learning ability of male rat offspring exposed to $\mathrm{AlCl}_{3}, \mathrm{NaF}$, and their combination, since the number of errors and elapsed time in the maze learning test were significantly higher than the corresponding normal values. Other studies reported that fluoride decreased the learning ability and memory of maze performance of rat offspring through modulating the activity of Glu metabolism-related enzymes, including Asp aminotransferase, alanine aminotransferase and glutamic acid decarboxylase, in the hippocampus ${ }^{[19,38]}$. Moreover, exposure to $\mathrm{NaF}$ during brain development induced cognitive deficits and anxiety-depressionlike behavior in mice ${ }^{[39]}$. The operant conditioning, the learning acquisition, and the activity of rat offspring were also decreased by prenatal exposure to aluminum $^{[40,41]}$. In addition, aluminum was able to impair the long-term potentiation in rat hippocampus by impairing the GluNOx/cyclic guanosine monophosphate pathway involved in some aspects of memory and learning ${ }^{[42,43]}$.

In the current study, the deficits in the learning behavior of rats exposed to $\mathrm{NaF}+$ $\mathrm{AlCl}_{3}$ were accompanied by the increase in IAAs in all tested brain area. Also, Gardiner and Belleroche ${ }^{[44]}$ found that fluoride alone increased the GABA level of the rat cerebral cortex. In addition, Shuchang et al. ${ }^{[45]}$ reported that rats exposed to $\mathrm{AlCl}_{3}$ showed deficits in learning and memory, as well as an increase in the GABA level of the neocortex. This effect was probably attributed to the inhibition of GABA re-uptake by the presynaptic cells and/or inhibition of GABA transaminase enzyme, which catalyzed the removal of amino group from GABA to produce the semialdehyde.

In conclusion, chronic exposure to $\mathrm{AlCl}_{3}$ and $\mathrm{NaF}$ combination induced an obvious retardation in the learning ability of rat offspring, possibly through agitating the brain EAAs, especially in the cerebral cortex and hippocampus.

\section{ACKNOWLEDGMENTS}

This research received no specific grant from any funding agency in the public, commercial or not-for-profit sectors. The author has no potential financial conflict of interest.

\section{REFERENCES}

[1] Lemire, J. and Appanna, V. D. (2011). Aluminum toxicity and astrocyte dysfunction: a metabolic link to neurological disorders. Journal of Inorganic Biochemistry, 105: 15131517.

[2] Shaw, C. A.; Seneff, S.; Kette, S. D. et al. (2014). Aluminum-induced entropy in biological systems: implications for neurological disease. 
J Toxicol, 2014: 491316 (DOI: 10.1155/2014/491316).

[3] Kawahara, M. and Kato-Negishi, M. (2011). Link between aluminum and the pathogenesis of Alzheimer's disease: the integration of the aluminum and amyloid cascade hypotheses. Int $\mathrm{J}$ Alzheimers Dis, 2011: 276393 (DOI: 10.4061/2011/ 276393).

[4] El-Demerdash, F. M. (2004). Antioxidant effect of vitamin $\mathrm{E}$ and selenium on lipid peroxidation, enzyme activities and biochemical parameters in rats exposed to aluminium. J Trace Elem Med Biol, 18: 113-121.

[5] DeVoto, E. and Yokel, R. A. (1994). The biological speciation and toxicokinetics of aluminum. Environ Health Perspect, 102: 940-951.

[6] Niswender, C. M. and Conn, P. J. (2010). Metabotropic glutamate receptors: physiology, pharmacology, and disease. Annu Rev Pharmacol Toxicol, 50: 295-322.

[7] Nayak, P. and Chatterjee, A. K. (2003). Dietary protein restriction causes modification in aluminuminduced alteration in glutamate and GABA system of rat brain. BMC Neurosci, 4: 4 (DOI: 10.1186/14712202-4-4).

[8] Petrik, M. S.; Wong, M. C.; Tabata, R. C. et al. (2007). Aluminum adjuvant linked to Gulf War illness induces motor neuron death in mice. Neuromolecular Med, 9: 83-100.

[9] Bondy, S. C. (2010). The neurotoxicity of environmental aluminum is still an issue. Neurotoxicology, 31: 575-581.

[10] Bondy, S. C. (2014). Prolonged exposure to low levels of aluminum leads to changes associated with brain aging and neurodegeneration. Toxicology, 315: 1-7.

[11] Fawell, J.; Bailey, K.; Chilton, J. et al. (2006). Fluoride in Drinking-Water. IWA publishing, London, UK.
[12] Choi, A. L.; Sun, G.; Zhang, Y. et al. (2012). Developmental fluoride neurotoxicity: a systematic review and meta-analysis. Environ Health Perspect, 120: 1362-1368.

[13] Chouhan, S. and Flora, S. (2008). Effects of fluoride on the tissue oxidative stress and apoptosis in rats: biochemical assays supported by IR spectroscopy data. Toxicology, 254: 61-67.

[14] Seraj, B.; Shahrabi, M.; Falahzade, M. et al. (2006). Effect of high fluoride concentration in drinking water on children's intelligence. Journal of Dental Medicine, 19: 80-86.

[15] Duan, Q.; Jiao, J.; Chen, X. et al. (2018). Association between water fluoride and the level of children's intelligence: a dose-response metaanalysis. Public Health, 154: 87-97.

[16] Jiang, S.; Su, J.; Yao, S. et al. (2014). Fluoride and arsenic exposure impairs learning and memory and decreases mGluR5 expression in the hippocampus and cortex in rats. PLOS ONE, 9: e96041 (DOI: 10.1371/ journal.pone.0096041).

[17] Sárközi, K.; Horváth, E.; Vezér, T. et al. (2015). Behavioral and general effects of subacute oral arsenic exposure in rats with and without fluoride. International Journal of Environmental Health Research, 25: 418-431.

[18] Abu-Taweel, G. M.; Ajarem, J. S. and Ahmad, M. (2012). Neurobehavioral toxic effects of perinatal oral exposure to aluminum on the developmental motor reflexes, learning, memory and brain neurotransmitters of mice offspring. Pharmacology Biochemistry and Behavior, 101: 49-56.

[19] Niu, R.; Sun, Z.; Cheng, Z. et al. (2009). Decreased learning ability and low hippocampus glutamate in offspring rats exposed to fluoride and lead. Environ Toxicol Pharmacol, 28: 254-258. 
[20] Kinawy, A. A. (2019). Synergistic oxidative impact of aluminum chloride and sodium fluoride exposure during early stages of brain development in the rat. Environ Sci Pollut Res Int. (DOI: 10.1007/s11356-019-04491-w).

[21] Kinawy, A. A. and Al-Eidan, A. A. (2018). Impact of prenatal and postnatal treatment of sodium fluoride and aluminum chloride on some hormonal and sensorimotor aspects in rats. Biol Trace Elem Res, 186(2): 441-448.

[22] Goma, A. A. and Mahrous, U. E. (2013). Ethological problems and learning disability due to aluminum toxicity in rats. Animal and Veterinary Sciences, 1: 12-17.

[23] He, L.-F. and Chen, J.-G. (2006). DNA damage, apoptosis and cell cycle changes induced by fluoride in rat oral mucosal cells and hepatocytes. World J Gastroenterol, 12: 1144-1148.

[24] Fulton, B. and Jeffery, E. H. (1990). Absorption and retention of aluminum from drinking water: 1 . Effect of citric and ascorbic acids on aluminum tissue levels in rabbits. Toxicological Sciences, 14: 788-796.

[25] Staddon, J. E. R. (2016). Adaptive Behavior and Learning. Cambridge University Press, Cambridge, UK.

[26] Heinrikson, R. L. and Meredith, S. C. (1984). Amino acid analysis by reverse-phase high-performance liquid chromatography: precolumn derivatization with phenylisothiocyanate. Anal Biochem, 136: 65-74.

[27] Hashimoto, K.; Sawa, A. and Iyo, M. (2007). Increased levels of glutamate in brains from patients with mood disorders. Biol Psychiatry, 62: 13101316.

[28] Nayak, P. and Chatterjee, A. K. (2001). Effects of aluminium exposure on brain glutamate and GABA systems: an experimental study in rats. Food Chem Toxicol, 39: 1285-1289.

[29] Yan-fei, H.; Shi-liang, X.; Chongsheng, B. et al. (2012). Effects of subchronic aluminum exposure on amino acids neurotransmitters in chicken brain. Journal of Northeast Agricultural University (English Edition), 19: 58-61.

[30] Yokel, R. A. (2000). The toxicology of aluminum in the brain: a review. Neurotoxicology, 21: 813-828.

[31] Guo, G. W. and Liang, Y. X. (2001). Aluminum-induced apoptosis in cultured astrocytes and its effect on calcium homeostasis. Brain Res, 888: 221-226.

[32] Forbes, W. F.; Gentleman, J. F. and Maxwell, C. J. (1995). Concerning the role of aluminum in causing dementia. Experimental Gerontology, 30: 23-32.

[33] Platt, B.; Fiddler, G.; Riedel, G. et al. (2001). Aluminium toxicity in the rat brain: histochemical and immunocytochemical evidence. Brain Res Bull, 55: 257-267.

[34] Joshi, J. (1990). Aluminum, a neurotoxin which affects diverse metabolic reactions. Biofactors, 2: 163-169.

[35] Cordeiro, J. M.; Silva, V. S.; Oliveira, C. R. et al. (2003). Aluminium-induced impairment of $\mathrm{Ca}^{2+}$ modulatory action on GABA transport in brain cortex nerve terminals. Journal of Inorganic Biochemistry, 97: 132-142.

[36] Kaya, M.; Kalayci, R.; Arican, N. et al. (2003). Effect of aluminum on the blood-brain barrier permeability during nitric oxide-blockade-induced chronic hyper-tension in rats. Biological Trace Element Research, 92: 221-230.

[37] Rui, D. and Yongjian, Y. (2010). Aluminum chloride induced oxidative damage on cells derived from hippocampus and cortex of ICR mice. Brain Res, 1324: 96-102.

[38] Pereira, M.; Dombrowski, P. A.; Losso, E. M. et al. (2011). Memory impairment induced by sodium fluoride is associated with changes in 
brain monoamine levels. Neurotox Res, 19: 55-62.

[39] Liu, F.; Ma, J.; Zhang, H. et al. (2014). Fluoride exposure during development affects both cognition and emotion in mice. Physiol Behav, 124: 1-7.

[40] Muller, G.; Bernuzzi, V.; Desor, D. et al. (1990). Developmental alterations in offspring of female rats orally intoxicated by aluminum lactate at different gestation periods. Teratology, 42: 253-261.

[41] Misawa, T. and Shigeta, S. (1993). Effects of prenatal aluminum treatment on development and behavior in the rat. The Journal of Toxicological Sciences, 18: 43-48.

[42] Platt, B.; Carpenter, D. O.; Busselberg, D. et al. (1995). Aluminum impairs hippocampal long-term potentiation in rats in vitro and in vivo. Experimental Neurology, 134: 73-86.
[43] Hermenegildo, C.; Sáez, R.; Minoia, C. et al. (1999). Chronic exposure to aluminium impairs the glutamate-nitric oxide-cyclic GMP pathway in the rat in vivo. Neurochemistry International, 34: 245-253.

[44] Gardiner, I. M. and de Belleroche, J. (1990). Modulation of gammaaminobutyric acid release in cerebral cortex by fluoride, phorbol ester, and phosphodiesterase inhibitors: differential sensitivity of acetylcholine release to fluoride and $\mathrm{K}^{+}$channel blockers. J Neurochem, 54: 11301135.

[45] Shuchang, H.; Qiaob, N.; Piyeb, N. et al. (2008). Protective effects of Gastrodia elata on aluminiumchloride induced learning impairments and alterations of amino acid neurotransmitter release in adult rats. Restor Neurol Neurosci, 26(6): 467473.

\section{How to cite this article:}

Kinawy, A. A. (2019). Effects of drinking water containing aluminum and fluoride salts on the learning behavior and brain neurotransmitters of male rat offspring. Egyptian Journal of Zoology, 71: 1-12 (DOI: 10.12816/ejz.2019.9821.1006). 


\section{تأثثير مياه الثرب المحتوية على أملاح الألومنيوم والفلوريد على سلوك التعلم والناقلات العصبية بدماغ ذلكور الأومنوم ذرية الجرذان}

\section{أمال عبدالجليل قناوى 19}

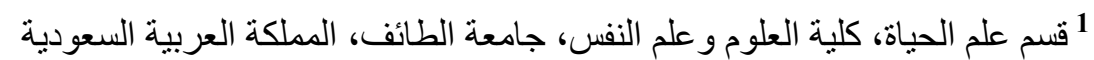

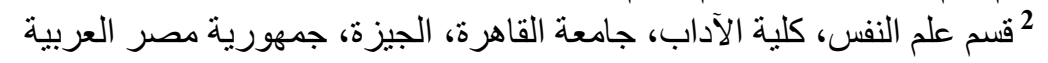

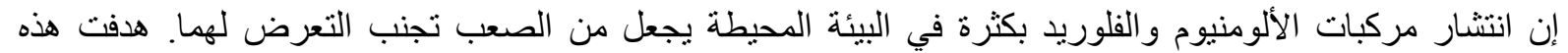

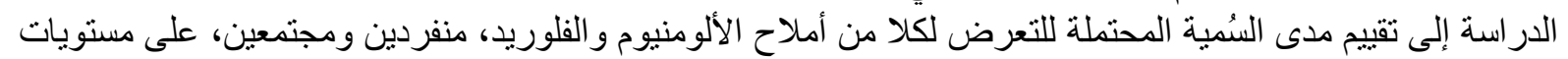

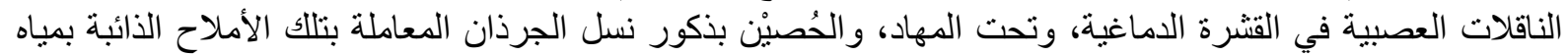

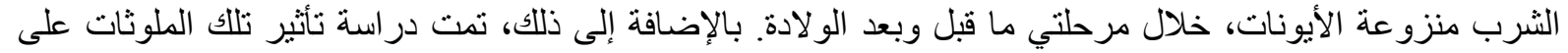

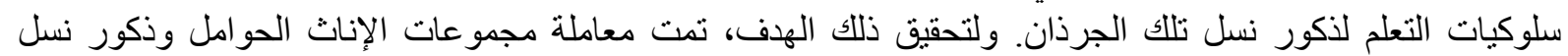

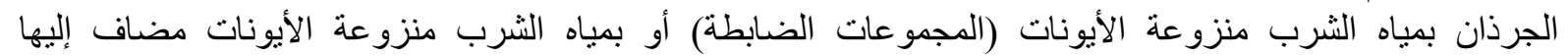

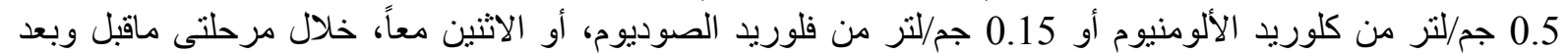

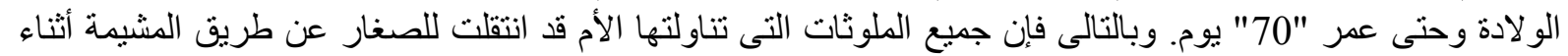

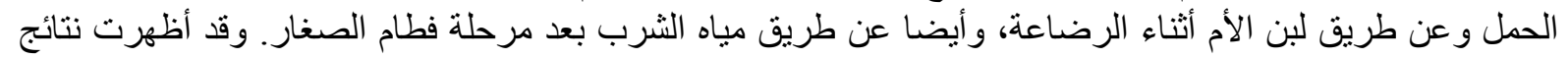

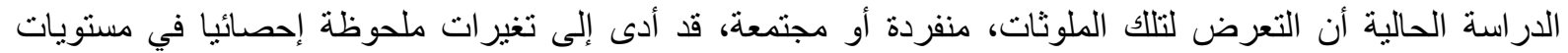

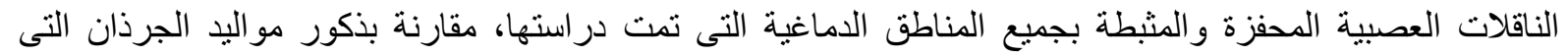

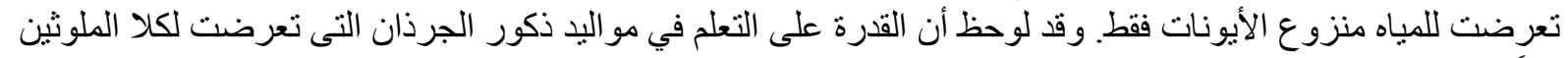

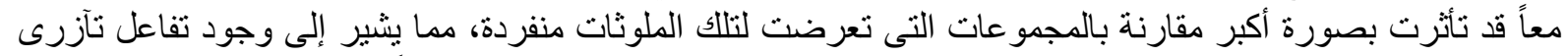

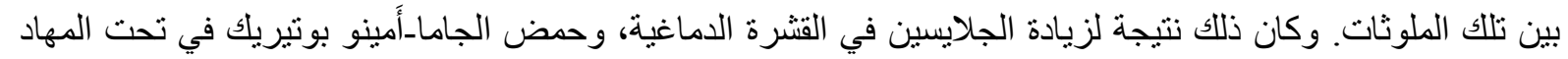
و الحُصنين، و أيضا الجلونامات في الحُصنين. 